\title{
Traffic Congestion in Bangladesh- Causes and Solutions: A study of Chittagong Metropolitan City
}

\author{
Robaka Shamsher ${ }^{1} \&$ Mohamamd Nayeem Abdullah ${ }^{2}$ \\ ${ }^{1}$ Lecturer, School of business, Independent University, Chittagong, Bangladesh \\ ${ }^{2}$ Lecturer, School of business, Independent University, Chittagong, Bangladesh
}

\begin{abstract}
One of the most challenging and complicated issues in city management in the present decade for Bangladesh is the traffic problem. It is a very common phenomenon in almost all the cities of Bangladesh. Presently, traffic congestion problem in Bangladesh are increasing at an alarming rate. The traffic problem has become to a very dangerous arena and has already implicit agonizing extent in the cities of Bangladesh. This type of study has been conducted in Dhaka but not in Chittagong city. Traffic management in Chittagong is not well organized as Dhaka so that the problem is becoming more complicated as the number of people in Chittagong is increasing and it is getting the priority after Dhaka. This article is dedicated to determine the current condition of traffic management in Chittagong City. This article explore the causes involved in traffic congestion including heavy concentration of vehicles, absence of adequate public transport, inadequate road infrastructure, faulty signaling equipment and poor enforcement of traffic rules. At the end of the paper the researchers tried to identify the solution of traffic jam in Chittagong Metropolitan City.
\end{abstract}

Keywords: Traffic congestion, vehicles, traffic rules, Chittagong Metropolitan City. JELclassfication: M10, M14

\section{INTRODUCTION}

U Jrbanization is a global phenomenon. It is taking place at a faster pace in the least developed Countries of the world like Bangladesh. Rapid and ongoing urbanization in Bangladesh has resulted in extreme levels of traffic congestion and extraordinary demands on infrastructure and service provision within the country's urban areas. Bangladesh is the world's most densely populated country with 993 people per squire kilometer (Bangladesh Economic Review 2011). Like other countries in the world, Bangladesh has also been experiencing intense traffic problem which is increasing day by day. It is becoming one of the most intolerable and burning issues for the country. The traffic problem has become to a very dangerous arena and has already implicit agonizing extent in the cities of Bangladesh (K.D.A, 2008). Traffic congestion is a common occurrence almost in all the cities of Bangladesh. Among the major urban cities like Dhaka, Chittagong, Khulna and Rajshahi especially the Dhaka city is now facing serious traffic problem along with drainage, housing, water, sewerage, gas and electricity scarcity (Osman, 2010). Monayem (2001) reveals that the average speed of a major road of Dhaka city, named "Mirpur road" is 15 to 17 kilometer per hour during peak period. According to Meenar, (2000) the annual country wise economic wastage caused by traffic jam was USD 79 million for the year 1997. The traffic congestion cost is USD 03 billion a year and the city losses over 08 million work hours daily (Osman, 2010). A developing country like Bangladesh cannot afford the economic and environmental loss resulted from this severe traffic obstruction (Naznin at. el., 2010).

Copyright (C) 2013, Asian Business Consortium | ABR
Limited resources invested for the development of transport facilities, the rapid population growth together with limited space available for new roads, coupled with the rapid rise in transport demand, existence of a huge number of non-motorized vehicles on roads, lack of application of adequate and proper traffic management schemes are producing severe transport problems in almost all the urban areas of Bangladesh. Worsening situations of traffic congestion in the streets and sufferings of the inhabitants from vehicle emissions demand extensive research in this field (Karim, 1997). Since the traffic problem in Bangladesh are increasing at an alarming rate, understanding the underlying issues regarding the urban problems like traffic jam, has become an area of interest by both academicians and practitioners. As such, the current study is an attempt to explore the causes and solution of traffic jam in Chittagong, the second largest city and commercial capital of Bangladesh.

With an estimated population of 4.1 million in an area of 177 sq. km. (CUS et al. 2006, p. 18), Chittagong is located in the southeastern coastal region of Bangladesh, for which this city is at risk of some dangerous natural environmental disasters including storm, cyclone (Karim, 1995), flash flood, landslides prompted by heavy rainfall (Quddusi, 2007) and earthquakes which cause many death almost every year in Chittagong. Besides these natural environmental disasters Chittagong is also experiencing a rapid growth of population because of rural urban migration (Taker, 1997; BBS 1981, 1991 and 2001). This expiation of population is making city dwellers life standstill on the roads of Chittagong during the rush hours of morning 
and evening due to traffic congestion. However there have been considerable researches on urban environmental issues like traffic congestion. But hardly any literature on Bangladesh especially for Chittagong city traffic congestion could have been found. Therefore, it is a commensurating step for the researchers to conduct this research which would help to identify the problems and solutions for traffic congestion for Chittagong city.

\section{LITERATURE REVIEW}

Traffic jam can be considered as one of the serious global problems for both developed and under developed countries (Naznin at. el. 2010). Traffic congested areas, especially in the urban areas traffic jams are an annoying and harmful problem to the residents and travelers. It is the consequence of discrepancy between transportation demand and supply (Habib, 2000). For the developing countries increases in urban population are creating pressure on the existing transportation system for which, traffic problem has already become a part of urban transportation system. In general, the development of transportation systems shaped the socio-economic benefit for any country. However, at the same time, this development is responsible for polluting the environment (Banerjee, 2009). Moreover numerous industrial activities are causing irrevocable damage to the enyironment (Ali, 2004; Chakraborty and Banerjee, 2007; Piccolo et. al., 2005; Singal, 2005). Consequently, the quality of life of the city dwellers is also getting annoyance by disturbance of sleep, interruption of daily activities and the like (Chhatwal et. al., 2005; Sommerhoff et. al., 2004).

Literature suggested that traffic noise caused adverse health effects on people (Al-Dakhllah and Jadaan, 2005; Anonymous, 1983; Chakraborty et. al., 1997; Chakraborty et. al., 2002). The traffic policemen in metropolitan cities are the most affected groups exposed to this dangerous factor during their working hours and in their leisure time (Omidvari and Nouri, 2009). According to Martin et. al., (2006) noise pollution occurred by traffic congestion is considered as one of the main problems of urban communities which has many hazardous effects on the urban environment. A study conducted by Skanberg and Ohrstrom (2002) and Bjork ET. Al, (2006) in the southern large cities of Sweden reveled that noise pollution caused by traffic jam is considered as one of the major problems for the Swedish population. Chien and Shih (2007) showed that any country's development is obstacle since traffic congestion resulted in a great deal of economic costs, discomfort costs and the like.

Generally, congestion means a number of things or people crowded together resulting difficulties in movement. Traffic congestion is a condition on road networks that occurs as use increases, and is characterized by slower speeds, longer trip times, and increased number of vehicles stand in line (Remi, at. el. 2009). The most common example is the physical use of roads by vehicles (Wikipedia, 2011).
When traffic demand is great enough that the interaction between vehicles slows the speed of the traffic stream, congestion is incurred. According to Adedimila (1977) traffic jam occurs when vehicles are fully stopped for a longer periods of time.

Traffic research still cannot fully predict under which conditions a "traffic jam" (as opposed to heavy, but smoothly flowing traffic) may suddenly occur (TTI, 2009). It has been found that individual incidents like car accidents or car braking when spread out heavily, sustained traffic jam suddenly occurs (Remi, at. el. 2009). According to Meenar (2000) Rickshaws are commonly blamed for the traffic chaos in Bangladesh, particularly in Dhaka city. Thus for reducing traffic jam Bangladesh Government has already banned rickshaws in certain chocks (A "chocks" is a central area where several streets meet) and major roads of Dhaka city. However in Chittagong and other urban cities rickshaw banning strategy has not yet implemented.

Traffic congestion primarily occurs due to the urban life styles where everyone wants to move at the same time. This is because of the efficient operation of both the economy and school systems required that people work, go to school and do their every day jobs about the same hours so that they can interact with each other (Remi, at. el. 2009). Peak-hour traffic congestion in almost all large and growing metropolitan regions around the world the same traffic problem exists. In fact, it is almost certain to get worse during at least the next few decades mainly because of rising population and wealth (Wikipedia, 2011). This will be true no matter what public and private policies are adopted to combat congestion.

\section{RESEARCh ObJective}

The broad objective of this study is to investigate the effect of traffic congestion on the urban population of Bangladesh especially in the city area. The present study has the following specific objectives:

1. To analyze the current condition of traffic management in Chittagong city.

2. To analyze the reasons behind traffic jam in the city.

3. To analyze the impact of traffic jam in Chittagong city.

4. To find out the solutions of traffic jam.

\section{Research Design and Methodology}

The methodology used for this study is literature survey. The study was completely based on compiling studies conducted so far on traffic congestion. In reviewing the literature, both theoretical and empirical studies were taken into consideration. This analysis clearly falls into the category of Qualitative research as it aims to get a deeper understanding of how urban environmental issues like traffic congestion is occurring, its overall impact on the quality of life of 
the city dwellers and some potential solution for this challenging problem. Secondary information was used to conduct this research. Secondary data were collected through content analysis from various published sources including books, online journals, newspapers, magazines, and reports. The publication manual of APA (American Psychological Association, 2001) was used for citation of the sources of references that have been used in the study.

\section{Traffic management in Chittagong City}

Intolerable traffic jams at the important roads in the port city have made lives of citizen miserable Chittagong. The traffic system of the city has already collapsed as the vehicles can't run on the main roads of the city due to congestion (The Independent, 2011); particularly the female, aged people and school-going students have been facing serious trouble due to traffic jam for disorderly movement of vehicles (News Network, 2010). Despite initiatives taken by the traffic authorities the main roads of the city are still blocked by traffic jams. The main factors involved in traffic congestion are a complex mix of traffic and heavy concentration of vehicles, absence of adequate public transport, inadequate road infrastructure, faulty signaling equipment and poor enforcement of traffic rules (SOS-arsenic.net, 2007). According to Rahman, (2008) in Chittagong the main traffic congestion occurred due to huge traffic flows and mixture of motorized and non-motorized vehicles ply at the same time in the main road intersections of the city.

Although the traffic rules and traffic police are assigned to control the traffic system but rickshaws and auto rickshaws mainly disregard red lights (SOS-arsenic.net, 2007) and signal lights at most of the busy intersections remained out order for a long time (News Network, 2010). Moreover the city accommodates huge numbers of light and medium scale industrial activities along with the CEPZ (Chittagong Export Pressing Zone). So a large number of people are migrating from surroundings villages to city everyday for getting job and food. A major portion of them involved themselves as Rickshaw puller and the rest engaged in port and other activities. So traffic congestions are increasing day by day due to ever-increasing population and traffic in the port city. Rahman, (2008) revealed that people of Bangladesh do not follow traffic rules properly and most of the drivers just do not obey speed limits. Moreoyer during the festival periods hawkers occupying the roads and footpaths which increase the traffic jam. Narrow streets in comparison with a number of vehicles are one of the rationales behind traffic congestion.

The main points of the city — including New Market, Station Road, GEC point, WASA point, Muradpur, Bohadderhat, Sholoshahar, Chalkbazar, Chittagong College area, Jamal Khan road, Anderkillah, Agrabad, Barik Buildings, Fakirhat, Chittagong Port gate area, Pahartoli, Alonker point, Katgor Bazar, Steel Mills Bazar, CEPZ point, Saltgolla, Kotowli point, Karnaphuli Bridge area, Kalurghat area, Oxygen point, Chittagong University ar-

Copyright (C) 2013, Asian Business Consortium | ABR ea, Kajirdewari, Lalkhan Bazar and other important points - are major spots for traffic congestion. Particularly, the prime roads from Katgor to Bohadder Hat, New Market to Chalkbazar to Bohadderhat, GEC point to Alonker point, Chittagong City to Chittagong University, New Market to Airport road are being continuously congested by motorized and non-motorized vehicles (The Independent, 2011).

\section{Reasons behind Traffic Congestion}

Increasing number of vehicle

In Bangladesh, population and traffic growth rate is approximately 1.5 and 7 percent respectively. But road expanding rate is not at all unmentionable with respect to higher traffic growth. As per BRTA (Bangladesh Road Transport Authority, 2010) source at present the total number of approved vehicle in Chittagong city is 84391 . Among these, Bus -2816, Autoricksha (Taxi)-20847, Tempo-4666, Motorcycle-13470, Jeep-1951, Car-15961, Pickup3656, Tank lorry-386, Tractor trailer-503, Truck-14065 and Micro-5998. So city roads are not capable to carry the traffic especially in the peak hours.

\section{Inadequacy of traffic police}

Traffic police in Chittagong is inadequate in numbers compared to other mega cities in Bangladesh. All the cross roads need at least four traffic police at a time whereas in Chittagong it is seen that the number of traffic police is always short and due to the lacking of proper instruction the vehicles are getting trapped in jam. Only 349 number of traffic police and 46 number of urgent (Source: Chittagong Metropolitan Police) are working in the city which is inadequate.

\section{Narrow roads}

Streets of Chittagong are not that wide spread, due to illegal possession on the road they are getting narrow and becoming a reason behind traffic jam. The major city roads in Chittagong are 100 to 120 feet. But most of the road have approximately 60 feet black top only. So every possibility is there to expand the road as per their right of way to reduce traffic congestion. Moreover this will be less expensive and less time consuming due to land acquisition will not be required in this process.

\section{Illegal Parking}

Illegal parking on the road has been creating congestion everyday from Tigerpass to Barik Building Moor, a distance of around two kilometres. On-road parking of vehicles is one of the main reasons behind serious traffic congestion on different parts of the port city including GEC, Muradpur, CDA Avenue, OR Nizam Road, Zakir Hossain Road, Station Road, Dhaka Trunk Road, Madarbari, Shuvapur Bus Stand, EPZ intersection and Olankar (Bangladesh Road Transport Authority, 2010).

\section{Increasing number of population}

All the thanas under Chittagong city is facing an increasing number of populations which is a bad indicator for the 
traffic management and this could be a vital reason behind traffic jam:

\section{Higher Purchasing power of the public}

Due to the higher purchasing power of the citizen of Chittagong the popularity of private transportation is increasing and but existing roads and highway are not supportive or changing according to the increasing number of vehicle. As a result vehicle congestion is increasing at an alarming rate.

\section{Improper planning of city development of CDA}

Chittagong Development Authority (CDA) has its long term city development planning. But that planning is not proper. Most of the time it is seen that the CDA is recovering some illegally ceased roadside land, but due to the corruption and vague development plan these kinds of movements are going in vain.

\section{Corruption in issuing driving license}

Driving license is issued by BRTA in Chittagong city but due to corruption people with few driving knowledge are getting the license. As a result the rate of accident is increasing; on the other hand due to violence of traffic rule traffic congestion is often seen. In the whole country the total number of illegal or without licensed driver is about 80000. People are becoming driver after working as a helper under a driver for few years.

\section{Improper lane management}

Lane management is an important fact in managing the traffic. In Dhaka city the most of the VIP roads and highway are of four lanes. But in Chittagong main management is very poor. Drivers rarely maintain the lane by themselves.

\section{Availability of rickshaw}

In Chittagong there is no restriction on route of the rickshaw. Unlike Chittagong in Dhaka city there are route restrictions for the rickshaw during the day time. All routes are open for rickshaw after 9.30 PM. As a slow and manual vehicle rickshaw can be blamed mostly for the vehicle congestion in the city of Chittagong. Other than that, most of the rickshaw pullers are having few or no knowledge about the traffic (SOS-arsenic.net, 2007).

\section{Fly over construction}

Flyover is under construction from Sholsohor to Bohoddarhat and another flyover is under construction in cement crossing for which people of Chittagong are going through some huge traffic congestion problem.

\section{SOLUTION OF TRAFFIC JAM}

\section{Clarity in BRTA}

BRTA should maintain transparency of their activity. Issuing driving license and transport fitness license should be monitored properly and proper steps should be taken in case of defaulters. Digital driving license should be intro- duced to control the fake driving license holding drivers.

\section{Strict lane management}

Different lanes for different types of vehicles should be marked on the roads and law i.e. financial penalty should be imposed to make the drivers maintain the lane.

\section{Restricting routes for Rickshaw}

Rickshaw should not be allowed in all the routes of the city. VIP routes like GEC circle, O R Nizam road, Badamtoli circle should be free from rickshaw. BRTA should take some responsibility to control the increasing number of rickshaws by imposing registration fee and legal documentation.

\section{Financial penalty to the traffic law breakers}

Government can take such strict step like imposing financial penalty on the law disobeying drivers. This trend is available in Dhaka. According to Remi, at el., (2009) policies should be made to dissuade the drivers from certain congestion-causing habit such as wrong overtaking, one way driving, disobey of traffic signals Mobile court should be introduced to fine the truck drivers for disobeying traffic law and driving unfit truck. This kind of implication of law can mitigate the traffic jam in short run, but in long run all the people should be involved to create awareness and responsible to the society. Otherwise traffic jam solution is impossible.

\section{Elevated Express way}

With over a year-long effort, the Bangladesh Bridge Authority (BBA) is yet to select the bidder to construct the DEE over the city. Initially it had been planned to give construction work without feasibility study. But the government has to scrap its decision in the face of various queries by the participating bidders. The pre-qualification bidding of the US dollar 2.0 billion project was opened on November 19, 2009 and its awarding may take one month's more time to complete. According to communication ministry the work will start in January after completing the signing of concessional agreements by this month. Till today, modalities of the agreement are yet to be finalized and the experts have still doubt about the completion of the first ever elevated expressway project before the end of the present government's tenure in 2013 as claimed by the minister. Such kind of advanced infrastructure development should be stepped for the city of Chittagong. The planning should be made now so that Chittagong city can enjoy the elevated express way in coming decade.

\section{Supply and demand}

Congestion can be reduced by either increasing road capacity (supply) or by reducing traffic (demand) (Remi, at el. 2009). Hermann, (2006) revealed that road capacity can be increased in a number of ways such as adding more capacity over the whole of a route or at bottlenecks, creating new routes, and improvements for traffic management. Reduction of demand can include, parking restriction, park and ride, congestion pricing, road space 
rationing, incentives to use public transport and introduction of e-education, e-shopping and home-based working options will reduce the number of people traveling.

\section{Bus route franchising}

Bus route franchising (BRT) is a concept applied in Dhaka, The country's first-ever bus route franchise (BRF) with digital ticketing system started its journey on UttaraAzimpur route in the city on 14th April, 2011. This process is going to reduce the hassle of the passengers. This kind of services should be implied in Chittagong as well.

\section{Building bus stoppages}

In Chittagong there are buses stoppages only where busses and other public transportation can stop and pick or drop the passengers, but these bus stoppages exist only in written form or legally. Rarely any public transportation will be found that stop according to the stoppage. Bus stoppage should be well developed in the city and the law enforcing authority should be aware of confirming the implication of law.

Increasing and developing the manpower (Traffic police) As the city is running with inadequate amount of traffic police than required, so it is almost must for the authority i.e. CMP to increase the number of traffic police. This step will create some scope for employment also. Only recruitment is not enough, they should be trained up for the betterment of the traffic management.

\section{Road widening}

Road widening is often advocated as ways to reduce traffic congestion. Roads of the city are narrow in different places, there are several reasons like Hawkers on the footpath and some portion of the road (scenario is regular in New Market area) and illegal possession on the road or illegal structures. This kind of unlawful activity has to be prevented by imposing proper law and city development plan. Several steps of road widening have been taken for example: Rirazuddoulla road, Andarkilla, Badurtala etc. However some research indicates that road widening provides only slight reductions in urban traffic congestion (TTI, 2009).

\section{Imposing tax on car and other private transportation}

Government is already charging a high amount of tax on imported cars and other private transports. Tax amount should be increased in order to reduce the amount of private transportation hence traffic congestion. But this formula is applicable after making the public transportation available, comfortable and convenient as well.

\section{Conclusion}

Traffic congestion is a global as well as local problem. All over the world, the prime cause of traffic congestion is on street parking (Naznin at el, 2010). In Bangladesh, traffic congestion is a common issue in the big cities like Dhaka, Chittagong and Khulna and in Dhaka it is severe. It is one of the most important problems of modern time. In Dhaka, dif- ferent infrastructural and managerial projects are granted for reducing traffic jam. However in Chittagong this type of policy is not addressed yet. Moreover development projects in Chittagong move slowly compared to Dhaka and development budget is also comparatively lower than Dhaka. For Chittagong, traffic congestion constraints can be ameliorated by embarking on various strategies such as road capacity expansion, improved road infrastructures, restricting routes for Rickshaw, financial penalty to the traffic law breakers, building bus stoppages and application of Fly over. Most importantly, proper traffic management system along with appropriate implementation of traffic rules is necessary to mitigate the problems of traffic congestion.

\section{REFERENCE}

Adedimila, A. S., 1981. "Toward improving traffic flow in Lagos", Transportation in Nigeria National development. Edited by S. O. Onakomaiya, NISER, and Ibadan.

Al-Dakhllah, A. N.; Jadaan, K. S., (2005). Attitudes of Jordanian population towards road traffic noise. Int. J. Appl. Sci. Eng., 3 (2), 145-150.

Anonymous, (1983). Noise pollution survey in Bombay, Scavenger, 3-9.

Banerjee, D, Chakraborty, S.K., Bhattacharyya S \& Gangopadhyay, A. (2009). Appraisal and mapping the spatial-temporal distribution of urban road traffic noise. Int. J. Environ. sci. Tech., 6 (2), 325-335.

Bangladesh Bureau of Statistics (BBS) (1981) Statistical Year Book of Bangladesh, ministry of Planning, government of Bangladesh, Dhaka.

Bangladesh Bureau of Statistics (BBS) (1991) Statistical Year Book of Bangladesh, ministry of Planning, government of Bangladesh, Dhaka.

Bangladesh Bureau of Statistics (BBS) (2001) Urban area report of Bangladesh, 1991, vol-1, Ministry of Planning, government of Bangladesh, Dhaka.

Bangladesh Road Transport Authority (BRTC), 2010

Bjork, J., Ardo, J., Stroh, E., Lovkvist, E., Ostergren, P. and Albin, M. (2006). Road traffic noise in southern Sweden \& its relation to annoyance, disturbance of daily activities and health. Scand. J. Work Environ. Health, 32(5), 392-401.

Centre for Urban Studies (CUS), National Institute of Population research and Training (NIPORT) and MEASURE Evaluation (2006), Slums of Urban Bangladesh: Mapping and Centre, 2005, Dhaka, Bangladesh and Chepel Hill, USA.

Chakraborty, D.; Santra, S. C.; Mukherjee, A. L.; Roy, B. M.; Das, P., (2002). Road traffic noise in Calcutta metropolis, India. Indian J. Environ. Health, 44 (3), 173-180.

Chakraborty, D.; Santra, S. C.; Mukherjee, A., (1997). Status of road traffic noise in Calcutta metropolis, India. J. Acoust. Soc. 101(2), 943-949.

Chakraborty, S. K.; Banerjee, D., (2007). A study of transport related noise pollution in Asansol town, West Bengal using modeling techniques. Nat. Environ. Pollute. Tech. 6 (4), 601- 607.

Chhatwal, G. R.; Mehra, M. C.; Satake, M.; Katyal, T.; Katyal, M.; Nagahiro, T., (2005). Environmental noise pollution and its control. Anmol Publications. New Delhi.

Chien, M. K. and Shih, L. H. (2007). An empirical study of the implementation of green supply chain management practices in the electrical and electronic industry and their relation to organizational performances. Int. J. Environ. Sci. Tech. 4 (3), 383 -394. 
Chittagong Metropolitan Police (CMP), 2009.

Habid, K.M.N. (2000). Evaluation of Planning Options to Alleviate Traffic Congestion and Resulting Air Pollution in Dhaka City.

Thesis paper.

http://www.newagebd.com/2005/dec/09/met.htm

http://www.sos-arsenic.net/english/environment/rickshaw.html\#1

K.D.A. (2008). Report on by pass road (Phase-ii), Government of the People 's Republic of Bangladesh.

Karim, M. (1997) Traffic Pollution in Bangladesh \& Metropolitan Dhaka a Preliminary investigation. Presented at the 90th Annual Meeting of A\&WMA, Toronto, Canada.

Karim, N (1995) Disasters in Bangladesh, Natural Hazards, 11(3), 247-258.

Martin, M.A., Tarrero, M.A., Gonzalez, A. and Machimbarrena, M. (2006). Exposure-effect relationships between road traffic noise annoyance and noise cost valuations in Valladolid, Spain. J. Appl. Acoust., 67 (10), 945-958.

Najneen, F., Hoque, K.S., Mahmood, S.M.S., Rahman, S., Sharmin, M. (2010) Traffic congestion due to unplanned activities on road-A case study on Gollamari-Satkhira, outer by-pass (Phase-II) and Gollamari-Batiaghata Road. Bangladesh research publications Journal. 4(2), 185-197.

News Network, October 8, 2010

Omidvari, M. and Nouri, J. (2009) Effects of noise pollution on traffic policemen Int. J. environ. Res., 3(4):645-652,

Osman, S. (2010) Dhaka's Traffic Problem - Opportunities and Suggested Solutions.

Piccolo, A.; Plutino, G.; Cannistraro, G., (2005). Evaluation and analysis of the environmental noise of Messina, Italy. Appl. Acoust.,
66 (4), 447-465.

Quddusi, (2007) 'Chittagong on the Precipice', the daily Star, June, 15.

Rahman, M. (2008) Urban environmental problems in Bangladesh: A case study of Chittagong Metropolitaon City. Thesis Paper.

Remi, A.J., Adegoke, A.A.I., Oyerinde, A.J. (2009) A Study of the Causes, Effects and ameliorative Measures of Road Traffic Congestion in Lagos Metropolis. European journal of Social Sciences $-11(1), 119-128$.

Singal, S. P., (2005). Noise pollution and control strategy, Narosa Publication. New Delhi

Skanberg, A. and Ohrstrom, J.F. (2002). Adverse health effects in relation to urban residential sound scopes. J. Sound Vib., 250(1), 151-155.

Sommerhoff, J.; Recuero, M.; Suarez, E., (2004). Community noise survey of the city Valdivia, Chile. Appl. Acoust., 65 (7), 643-656.

Taker, M A (1997) City port: Chittagong City corporation, Submitted to 2nd study course on specific fields of urban policy, conducted by Asian urban Centre of Kobe, Japan, from september 28 to October 12 www.auick.org, (Access December 15 2006).

Texas Transportation Institute (2009) "Components of the congestion problem", 2005 urban areas totals. Retrieved on 10/06/2009.

The Independent, March 6, 2011.

UNESCAP (2007). Local Government in the Asia and the Pacific: A comparative study, country Paper: Bangladesh, www.Unescap.org, (Accessed November 22 2007) Wikipedia, the free encyclopedia 20 October, 2011.

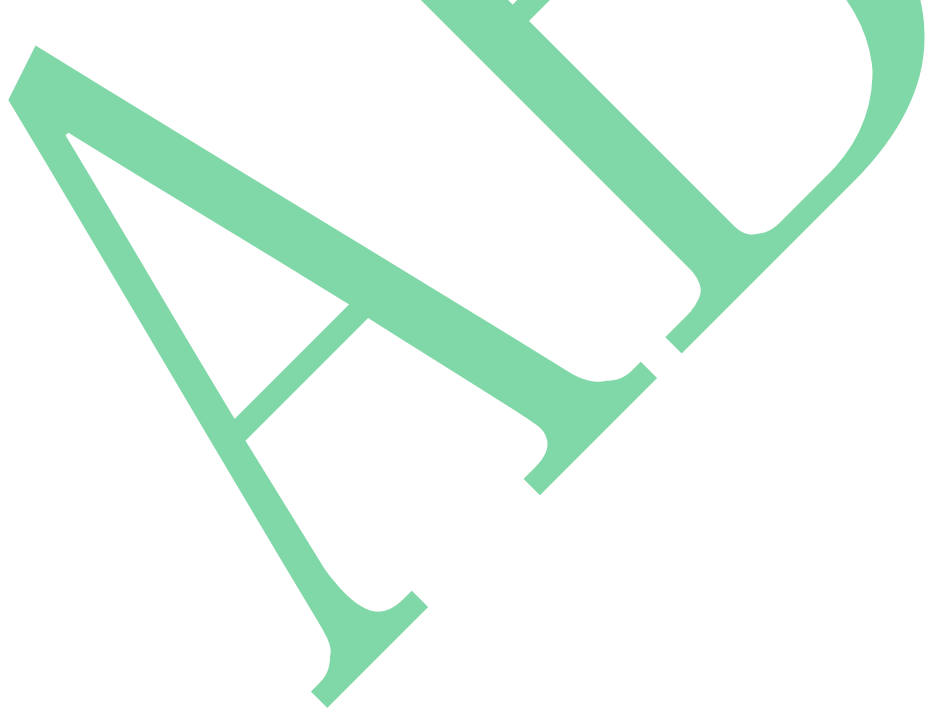

